\title{
Correction to: Risk factors of premature rupture of membranes in public hospitals at Mekele city, Tigray, a case control study
}

Natnael Etsay Assefa ${ }^{*}$, Hailemariam Berhe, Fiseha Girma, Kidanemaryam Berhe, Yodit Zewdie Berhe, Gdiom Gebreheat, Weldu Mamu Werid, Almaz Berhe, Hagos B. Rufae and Guesh Welu

\section{Correction to: BMC Pregnancy Childbirth https://doi.org/10.1186/s12884-018-2016-6}

Following publication of the original article [1], we have been notified that the name of one author was spelled incorrectly as Kidanemariam Berhe, when the correct spelling is Kidanemaryam Berhe.

Published online: 13 January 2020

\section{Reference}

1. Assefa, et al. BMC Pregnancy Childbirth. 2018;18:386 https://doi.org/10.1186/ s12884-018-2016-6.

The original article can be found online at https://doi.org/10.1186/s12884018-2016-6

*Correspondence: natty416@gmail.com

Adigrat University College of Health Sciences, Adigart, Tigray, Ethiopia 